Filol. linguíst. port., São Paulo, 15(2), p. 385-406, Jan./Jun. 2013.

DOI: http://dx.doi.org/10.11606/issn.2176-9419.v15i2p385-406.

\title{
Para o estudo da denominação da cor em português: estrutura e significado dos nomes e adjetivos construídos ${ }^{1}$
}

Towards the study of color naming in Portuguese: structure and meaning of constructed nouns and adjectives

\author{
Margarita Correia \\ Universidade de Lisboa, Portugal. \\ mcf@iltec.pt \\ Sílvia Barbosa \\ Instituto de Linguística Teórica e \\ Computacional, Portugal. \\ silvia.iltec@gmail.com
}

\begin{abstract}
Resumo: A nomeação da cor é um importante objeto de estudo em lexicologia, embora a descrição morfológica dos processos nela intervenientes em português ainda apresente lacunas. Neste trabalho, pretendemos levar a cabo a descrição dos aspetos morfológicos e semânticos dos nomes e adjetivos construídos com base nos nomes de cor básicos do português. Em particular, propusemo-nos descrever a estrutura interna dos nomes e adjetivos de cor, dando conta de aspetos relacionados com a produtividade dos processos de construção de palavras envolvidos, associando esses elementos com as capacidades referenciais dessas palavras. Foram usados dados lexicográficos, recolhidos no Vocabulário Ortográfico do Português, e a análise
\end{abstract}

\footnotetext{
${ }^{1}$ Agradecemos a José Pedro Ferreira, investigador do ILTEC, a leitura atenta e as muitas e pertinentes sugestões dadas. Agradecemos a Andrew Swearingen, investigador do ILTEC, pela revisão do resumo em inglês. Porém, quaisquer falhas ou incorreções são da exclusiva responsabilidade das autoras.
} 
enquadra-se no modelo teórico de descrição de morfologia construcional SILEX. Determinámos que a sufixação é o processo que mais ocorre, seguido da composição. A prefixação é inexpressiva. Verificámos, ainda, que existem diferenças entre os nomes e adjetivos derivados e os nomes e adjetivos compostos no que diz respeito à denominação da cor. A sufixação permite sobretudo nomear tons, mas de forma pouco precisa, ao passo que os compostos são mais eficazes na nomeação de tons e constituem o recurso mais eficiente para a denotação de graus de luminosidade da cor.

Palavras-chave: denominação da cor, construção de palavras, morfologia, lexicologia

\begin{abstract}
Color naming is a central study subject in Lexicology, although its systematic morphological description in Portuguese is still lacking. In this study we describe the morphological and semantic aspects of complex nouns and adjectives constructed on the basis of the basic color terms from the Portuguese language. We focus on a description of the internal structure of these complex words, as well as on aspects concerning the productivity of the morphological processes, and attempt to associate those aspects with the referential capacities of the studied words. Lexicographical data were used, collected from the Vocabulário Ortográfico do Português, and the theoretical framework of this research is SILEX's constructional model of Morphology. We verified that suffixation is the most productive process, followed by composition. Prefixation is rather unproductive. There are differences in the way that derived nouns and adjectives, on the one hand, and compounds, on the other, may name color tones and degrees of saturation. Derived words give rise to the naming of tones in a very imprecise manner, while compounds are much more effective and precise in the way they may name them, and composition is the most efficient resource available to denote degrees of brightness.
\end{abstract}

Keywords: color naming, word-formation, morphology, lexico$\log y$

\title{
1 Introdução
}

A denominação da cor em qualquer língua é um dos objetos de estudo mais aliciantes para o lexicólogo, pois ela encontra-se na base de uma das discussões 
linguísticas mais interessantes: a que se desenvolve entre os universalistas, para quem é possível postular universais semânticos que determinam a nomeação da cor nas mais diversas línguas, e os relativistas, para quem cada língua recorta e categoriza o mundo e, consequentemente, também o espetro da luz, de uma forma especial e única.

Ainda que a nível internacional tenham surgido nos últimos anos diversas publicações de relevo (e.g. Hardin \& Maffi Eds. 1997; Steinvall 2002² ; Biggam \& Kay Eds. 2006; MacLaury, Paramei \& Dedrick Eds. 2007; Plümacher \& Holz Eds. 2007; Biggam, Hough, Kay \& Simmons Eds. 2011) e tenham ocorrido grandes eventos internacionais sobre o tema (e.g. PICS04, PICS08 e PICS12 ${ }^{3}$ ), estranhamente, salvo raras exceções, a denominação das cores é um tema pouco estudado em Portugal e em relação ao português europeu (PE) - constituem exceções trabalhos como Carvalho 1994, Correia 1999, 2006 e Swearingen 2002. Já para o português do Brasil (PB), despontam numerosos trabalhos, como os de Said Ali 1931, C. Zavaglia 1998, 2006, 2008, C. Zavaglia \& A. Zavaglia, 2000, 2007, entre outros.

O objetivo deste trabalho é levar a cabo uma descrição dos aspetos morfológicos dos nomes e adjetivos passíveis de denominar cores e tons registados no Vocabulário Ortográfico do Português (Correia Coord. 2010), partindo das denominações usadas para as cores básicas do Português. Em particular, propomo-nos descrever a estrutura interna desses nomes e adjetivos, dando conta de aspetos relacionados com a produtividade dos processos de construção de palavras envolvidos, associando esses elementos às capacidades referenciais dos produtos analisados. Com este trabalho, pretendemos contribuir para estimular o desenvolvimento de outros trabalhos na área, nomeadamente trabalhos contrastivos entre diferentes variedades do português.

Na primeira parte, definimos o conceito de nome de cor básico usado neste trabalho e referimos algumas particularidades do português no que toca a este campo semântico. Em seguida, apresentamos a metodologia e o quadro teórico escolhido e procedemos à descrição dos dados, para, finalmente, os analisarmos e aduzirmos algumas conclusões.

\footnotetext{
${ }^{2}$ Esta obra, uma tese de doutoramento, constitui uma excelente introdução ao estudo linguístico da denominação da cor e está disponível em: umu.divaportal.org/smash/get/diva2:144764/FULLTEXT01.

${ }^{3}$ PICS - Progress in Colour Studies, congresso internacional com edições em 2004, 2008 e 2012, organizado pela Universidade de Glasgow, no Reino Unido.
} 


\section{Nomes de cor}

Neste trabalho, tomaremos como ponto de partida Carvalho 1994 e entenderemos nome de cor como "uma palavra ou grupo de palavras mais ou menos fixo (com graus diferentes de lexicalização, (...) que possa, em certos contextos, designar uma determinada cor ou matiz de uma cor" (Carvalho 1994: 76).

De acordo com Berlin \& Kay (1969/1999: 6-7), para classificar um nome de cor como nome de cor básico é necessário que ele exiba as seguintes caraterísticas: 1) seja monolexemático; 2) o seu significado não esteja contido no de nenhum outro nome de cor básico; 3) a sua aplicação não seja restrita a uma classe de objetos; 4) seja psicologicamente relevante para os falantes. Em casos de dúvida relativamente a palavras que possam ser consideradas potenciais nomes de cor básicos são aplicáveis os critérios subsidiários seguintes: 5) a forma em causa terá de ter a mesma distribuição que a dos termos básicos já estabelecidos; 6) termos que designem objetos com uma cor caraterística são duvidosos; 7) palavras de proveniência estrangeira são duvidosas; 8) unidades de estrutura morfológica complexa são à partida pouco aptas a assumirem o papel de nomes de cor básicos.

A língua portuguesa encontra-se no estádio VII de desenvolvimento, possuindo 11 ou 12 termos de cor básicos, apresentados no Quadro 1, de acordo com a proposta de classificação, de cariz universalista e evolucionista, de Berlin \& Kay (1969/1999: 22-23).

\begin{tabular}{cccccccc}
\hline $\mathbf{I}$ & II & IIIa & IIIb & IV & V & VI & VII \\
\hline $\begin{array}{l}\text { preto / } \\
\text { negro }\end{array}$ & vermelho & & & verde & azul & castanho $^{4}$ & cinzento \\
& & verde & amarelo & & & & $\begin{array}{c}\text { rosa } \\
\text { roxo } \\
\text { branco }\end{array}$ \\
& & & & & & & laranja \\
\hline
\end{tabular}

Quadro 1: Os nomes de cor básicos do português.

Grosso modo, de acordo com a proposta de Berlin \& Kay 1969/1999, línguas que se encontram no estádio I de desenvolvimento apresentam apenas dois nomes de cor básicos (genericamente para as cores preta e branca); línguas no estádio VII, como é o caso da língua portuguesa, apresentam 11 ou 12

\footnotetext{
${ }^{5}$ Em PB, o termo equivalente é marrom.

${ }^{5}$ Preto e negro correspondem a duas denominações concorrentes para a mesma cor, como se explicará adiante.
} 
nomes de cor básicos; línguas em estádios intermédios apresentam três, quatro, cinco, seis e sete termos, na sequência que a leitura da esquerda para a direita e de cima para baixo do Quadro 1 permite observar.

Os nomes de cor básicos em português apresentam algumas particularidades interessantes quando comparados com os de outras línguas, nomeadamente as demais línguas românicas.

Em primeiro lugar, de acordo com a pesquisa desenvolvida em trabalho anterior $^{6}$ para a nomeação da cor negra, seguindo os critérios propostos por Berlin \& Kay e a análise de dados de corpora, constatou-se que parece existir em português não um, mas dois termos básicos de cor - preto e negro -, facto que, a confirmar-se, colocaria a língua portuguesa em posição semelhante à das línguas russa e húngara, que possuem 12 nomes de cor básicos ${ }^{7}$. Esta situação resulta de uma mudança diacrónica: preto ocorre desde os primórdios da língua, ao passo que negro surge no século XVI e toma progressivamente terreno em relação a preto, pelo menos no registo escrito ${ }^{8}$, sendo que, atualmente, em PE, ambos os termos coexistem, mas distribuem entre si os tipos de categorias que podem nomear e/ou qualificar, assim como o registo linguístico em que são utilizados (preto é mais popular e usado na oralidade, ao passo que negro ocorre predominantemente na escrita, em registos mais formais e especializados e no género lírico).

Em segundo lugar, relativamente ao par vermelho / encarnado, Correia 2006 determinou que, em PE, vermelho constitui o nome de cor básico, ao passo que encarnado, além de ser mais recente na língua como nome de cor, tem uso mais restrito do ponto de vista denominativo e é sociolinguisticamente marcado.

Também o termo roxo apresenta uma história particular. Roxo é proveniente do latim russěu-, que deu origem em outras línguas românicas a cognatos que denominam a cor vermelha (e.g. rouge em Francês, rojo em Espanhol, rosso em Italiano) - cf. Said Ali 1931, Swearingen 2002. No caso do português, o termo foi progressivamente substituído nessa qualidade pela forma vermelho, assumindo o valor que hoje se lhe conhece.

\footnotetext{
${ }^{6}$ Comunicação apresentada ao congresso Progress in Colour Studies 2008 (PICS08), intitulada "Preto and negro, two terms to name black colour in Portuguese their specific meaning and use".

${ }^{7} \mathrm{O}$ russo apresenta dois termos para a cor azul, ao passo que o húngaro apresenta dois termos para a cor vermelha - cf. Berlin \& Kay (1969/1999: 35-36).

${ }^{8}$ Análise realizada com base nos dados de Davies \& Ferreira (2006- ).
} 
Por fim, é de notar que castanho, rosa e laranja são originalmente nomes de objetos que possuem essa cor de forma estereotípica e que cinzento não é uma palavra simples, mas sim um derivado por sufixação que toma por base cinza, também nome de objeto.

Como se sabe, cada uma das formas referidas corresponde em português a duas unidades lexicais: uma correspondente a um nome masculino, o nome da cor, e outra correspondente a um adjetivo. Não trataremos neste trabalho dos processos de conversão envolvidos na criação destas unidades ${ }^{9}$.

Além das formas apresentadas, existem em português muitos outros nomes e adjetivos de estrutura morfológica aparentemente simples para a nomeação de cores e tons - alguns tomados, por metonímia, de objetos que tipicamente ostentam a cor referida, tais como turquesa, violeta, carmim, bronze, ouro, ou prata - que podem dar origem a derivados e compostos, dos quais não trataremos neste trabalho. A nossa análise centrar-se-á nos derivados e compostos que têm como base os nomes constantes do Quadro 1.

No estudo da denominação da cor é normalmente utilizado o sistema de Munsell, que constitui um dos mais antigos sistemas para a medição e a notação das cores. De acordo com este sistema, o espetro cromático organiza-se em função de três dimensões:

- o tom ou matiz (hue), que estabelece a posição de cada cor tomando como referência as cores fundamentais do arco-íris;

- a luminosidade ou valor (brightness), que indica o grau de claridade, i.e., a posição numa escala que se situa entre 0 (negro absoluto) e 10 (branco absoluto);

- a saturação ou croma (saturation), que indica a intensidade de pigmentação ou grau de saturação da cor $^{10}$ - cf. Munsell $1961^{11}$ apud Steinvall 2002: 11-12.

A consideração destas dimensões será interessante para a descrição da semântica dos dados tratados.

${ }^{9}$ Para uma descrição dos processos de conversão envolvidos na formação de nomes de cor, consulte-se Correia 1999 (capítulo 3) e Correia 2002.

${ }^{10} \mathrm{~A}$ terminologia da cor, das suas categorias e conceitos associados não se encontra estabilizada, não apenas em português mas também em inglês, variando drasticamente, por exemplo, em função do sistema de notação usado. Na redação deste excerto em português e em particular na seleção dos equivalentes portugueses para os termos ingleses hue, brightness e saturation, socorremo-nos do artigo "Munsell (cartas das cores)" de E. P. Cardoso Franco, da Enciclopédia LusoBrasileira de Cultura (Lisboa: Verbo, 2001, vol. 20).

${ }^{11}$ Munsell, A. H. 1961. A Color Notation. $11^{\text {th }}$ ed. Baltimore: Munsell Color Company. 
Para o estudo da denominação da cor em português...

\section{Metodologia}

Os dados usados neste trabalho são de natureza lexicográfica. Neste apartado, após descrever sumariamente a sua fonte, o Vocabulário Ortográfico do Português, descreveremos sumariamente a metodologia usada para a sua recolha e seleção.

\subsection{Dados para análise}

O Vocabulário Ortográfico do Português (VOP) é uma base de dados morfológicos disponível no sítio www.portaldalinguaportuguesa.org. O VOP contém mais de 210 mil entradas com as respetivas formas flexionadas, mais de 1,5 milhões, assim como uma série de outras informações formais associadas a cada entrada: categoria morfossintática, divisão silábica e marcação de sílaba tónica, variação, relações funcionais. O VOP baseia-se em fontes lexicográficas, nomeadamente Rebelo Gonçalves 1966, mas foi enriquecido com dados recolhidos em corpora tais como o CETEMPúblico (Rocha \& Santos 2000), assim como em neologismos recolhidos no Observatório de Neologia do Português $(\mathrm{ONP})^{12}$.

O VOP tornou-se instrumento oficial para a aplicação do Acordo Ortográfico da Língua Portuguesa de 1990 em Portugal com a publicação, em Diário da República, da Resolução do Conselho de Ministros n. ${ }^{\circ}$ 8/2011, de 25 de janeiro de 2011. Além disso, a base de dados e a estrutura computacional em que se encontra alojada foram cedidas ao Instituto Internacional de Língua Portuguesa (IILP), de modo a constituir a base do que virá a ser o Vocabulário Ortográfico Comum da Lingua Portuguesa - cf. Ferreira et alii 2012.

O facto de estes dados serem pesquisáveis (diferentes tipos de pesquisa, consoante o que se pretenda extrair da base de dados) através de ferramentas computacionais específicas permite levar a cabo buscas que dão conta de regularidades que afetam grandes porções do léxico do português, o que tornou possível a elaboração de vários recursos também disponíveis no Portal da Língua Portuguesa, tais como o Dicionário de Nomes Deverbais, Dicionário de Nomes Deadjetivais de Qualidade, Dicionário de Gentílicos e Topónimos, Dicionário de Estrangeirismos, Vocabulário de Mudança, assim como o Lince, um conversor para a nova ortografia.

As possibilidades de pesquisa que o VOP oferece tornam-no não apenas um instrumento de consulta útil para o grande público (o VOP conta atualmente com uma média de 7,5 milhares de utilizadores únicos por dia), como também, uma excelente fonte de dados para a pesquisa em linguística.

${ }^{12} \mathrm{Cf}$. Antunes 2012 para uma descrição detalhada do trabalho desenvolvido no ONP, bem como dos dados obtidos entre 2004 e 2011. 


\subsection{Seleção dos candidatos}

Inicialmente, foi feita uma extração semiautomática dos potenciais nomes e adjetivos de cor, tomando por base a grafia do radical e suas variantes ortográficas - ex.: (-)branc- e (-)branqu-. Este processo devolveu uma lista de 810 candidatos a nomes e adjetivos de cor.

Posteriormente, realizou-se uma seleção manual de forma a excluir os falsos candidatos. Dessa lista foram excluídos 590 itens, que apresentavam pelo menos uma das características abaixo:

- palavras como impreterivelmente, em que surge a sequência de caracteres pret-, mas que provém de preterir e não de preto;

- palavras com categoria gramatical diferente de nome ou adjetivo - verbos como verdejar ou negrejar;

- formas de nomes animados femininos - porque o VOP regista o masculino e o feminino dos nomes em paradigmas separados;

- palavras derivadas de topónimos que incluem denominações de cor - e.g. cabo-verdiano de Cabo Verde, montenegrino de Montenegro.

Foram, também, excluídos da lista de candidatos todos os nomes que, ainda que correspondessem a potenciais nomes de cor ou fossem derivados deles, não apresentavam nos dicionários gerais de língua consultados (Casteleiro. Coord. 2001 - DLCP; Costa \& Silva. Coords. 2010 - GDLP) qualquer aceção como nomes de cor, mas apenas como entidades (objetos, pessoas, animais, plantas, substâncias) que são nomeadas a partir da cor que prototipica ou estereotipicamente apresentam, dado que a cor é uma das características mais relevantes e distintivas quando do processo de categorização da realidade e.g. peles-vermelhas: «ETNOGRAFiA tribos aborígenes da América do Norte e da América do Sul» (GDLP); azul da prússia: «QUímICA substância de cor azul-escura, ligeiramente esverdeada, usada em tintas, vernizes, etc.» (GDLP).

Foram também excluídos da lista os adjetivos que contêm um radical de cor, mas que qualificam entidades muito específicas (e.g. infravermelho para um determinado tipo de radiação eletromagnética), ou partes do corpo (de animais e pessoas) que exibem a cor em causa (e.g. crinipreto, barbinegro).

O corpus de nomes e adjetivos de cor comporta um total de 210 unidades que foram descritas de acordo com os parâmetros indicados no Quadro 2, que contém apenas dois itens, em jeito de exemplificação. 
Para o estudo da denominação da cor em português...

\begin{tabular}{|c|c|c|c|c|c|c|}
\hline Classe & Item & Etimologia & Aceções & Fonte & $\begin{array}{l}\text { Descrição } \\
\text { Formal }\end{array}$ & Estatuto \\
\hline adjetivo & brancaço & $\begin{array}{c}\text { De branco }+ \\
\text {-aço }\end{array}$ & $\begin{array}{c}\text { quase branco; } \\
\text { brancacento; } \\
\text { alvacento }\end{array}$ & DLPC & $\mathrm{N}$ (cor) & aceite \\
\hline nome & entreverde & $\begin{array}{l}\text { De entre- } \\
+ \text { verde }\end{array}$ & $\begin{array}{l}\text { vinho dessa } \\
\text { casta de uva [da } \\
\text { região do Douro] }\end{array}$ & DLPC & $\mathrm{N}$ (cor) & rejeitado \\
\hline
\end{tabular}

Quadro 2: Exemplos do corpus

\section{Enquadramento teórico}

A análise morfológica que se segue é baseada no modelo SILEX, desenvolvido por Danielle Corbin (1987, 1991, 1997), aplicado à descrição dos nomes de qualidade do português por Correia 1999 e no qual se baseia a descrição proposta por Correia \& Almeida 2012. Constituem também aplicações deste modelo ao português, por exemplo, os trabalhos de Rio-Torto, (1991, 1993, 1998).

Uma das caraterísticas deste modelo de descrição morfológica é o facto de ser associativo, partindo-se do princípio de que, na construção de uma palavra, são gerados pelo mesmo processo a estrutura morfológica e o significado da palavra construída. O modelo é também estratificado, na medida em que estabelece que os diferentes tipos de significado que as palavras construídas assumem (descritivo / referencial, instrucional e enunciativo) são constituídos em várias etapas do processo de construção de palavras. Para tratar da semântica de indivíduos lexicais de uma língua - simples, complexos não construídos e construídos - o modelo incorpora uma série de contribuições da semântica lexical, em particular da semântica cognitiva (cf. Corbin 1991 e 1997, Correia 1999, capítulo 1).

O modelo SILEX tem também como um dos seus pressupostos o de que a escolha de uma estrutura morfológica para a denominação de uma categoria, entre várias possíveis num sistema linguístico, não é totalmente aleatória e que é determinada concomitantemente pelas caraterísticas semânticas dessa estrutura, pelas suas capacidades referenciais e pela forma como se pretende dar a ver essa categoria no momento da nomeação. Como se verá adiante, a análise dos dados deste trabalho apoia esta perspetiva. 


\section{Análise dos dados}

Excluindo os nomes de cor básicos atrás referidos, ocorrem em português nomes e adjetivos construídos por derivação por afixação (prefixação e sufixação) e composição. Nas linhas que se seguem, proceder-se-á à descrição das estruturas morfológicas resultantes destes processos.

\section{A. Afixação}

A.1. Prefixação (prefixo + nome de cor)

entrebranco, ultravermelho

São apenas dois os exemplos desta estrutura recenseados, ambos adjetivos deadjetivais, o que nos leva a acreditar que este não é um processo disponível em português. Entrebranco é definido lexicograficamente como «quase branco, esbranquiçado» (GDLP); por seu turno, ultravermelho, além da aceção respeitante à Física, apresenta (em DLPC) uma aceção não especializada, descrita como: «que tem um tom vermelho muito forte, muito carregado.» Partindo da descrição lexicográfica, pode verificar-se que estes adjetivos têm significado avaliativo. Poder-se-ia pensar que se trata de um par de afixos opostos; porém, uma análise mais atenta permite-nos verificar que, enquanto entrebranco denota um tom de branco, ultravermelho denota um grau saturado de vermelho.

A.2 Sufixação (nome de cor + sufixo)

A.2.1 Adjetivos deadjetivais apresentando os seguintes sufixos:

-ach- - verdacho

- aç- - brancaço

- ão - azulão, vermelhão

-inh- - vermelhinho

-uç- - vermelhuço

-usc- - vermelhusco

Todos os sufixos recenseados nestas estruturas fazem parte do paradigma dos sufixos que permitem a construção de adjetivos deadjetivais avaliativos (cf. Rio-Torto 1993), muitas vezes com marca semântica pejorativa - cf. friacho, atrevidote, gordalhuço, pardusco (dados do VOP), e também Rio-Torto 1993.

Não é consensual a determinação do estatuto categorial das bases dos derivados elencados ao longo de A.2., pois ela depende do quadro teórico de morfologia que se assume. Não cabendo neste âmbito a discussão desta questão, seguimos, ao longo da pesquisa, as premissas postuladas em diferentes trabalhos realizados no quadro do modelo SILEX de morfologia construcional, 
particularmente em Corbin, D. \& P. 1991, Correia 1999 (capítulo 3), Correia 2002 e Mélis-Puchulu 1991.

A produtividade destes sufixos, nos dados recolhidos, é baixa (na maioria com apenas uma ocorrência). No entanto, o reduzido número de unidades construídas por este processo poderá ficar a dever-se não tanto à falta de produtividade destes sufixos, mas à não dicionarização de formas construídas com eles, devido a, por um lado, os produtos derivados pertencerem em geral a registos familiares, populares, ou regionais e serem predominantemente usados na oralidade, e, por outro, por se tratar de formas semanticamente transparentes apenas registadas lexicograficamente quando apresentam significados lexicalizados. Registe-se ainda que são possíveis em português unidades como ${ }^{\circ}$ azulacho, ${ }^{o}$ vermelhaço, ${ }^{\circ}$ castanhuço, ${ }^{\circ}$ cinzentusco ${ }^{13}$.

Foi detetada a forma verdasto, dada como sinónimo de verdasco, mas não consideramos que - ast- possa ser incluído no elenco dos sufixos disponíveis em português para a construção de adjetivos deadjetivais ${ }^{14}$. Acresce ainda a menção a apenas quatro formas de superlativo absoluto sintético em -issimo dicionarizadas, entre as muitas possíveis, a saber, amarelíssimo, azulíssimo, branquíssimo e negríssimo. Esta situação decorre da falta de sistematicidade dos dicionários na inserção de entradas nas nomenclaturas respetivas.

Verifica-se que, embora todos os adjetivos deste grupo sejam construídos pelo mesmo processo de construção, nem todos apresentam o mesmo tipo de denotação. Com exceção dos adjetivos em - ão e -inh-, todos eles denotam tons das cores referidas pelas respetivas bases, embora o façam de forma vaga, imprecisa, pois não é possível precisar qual a posição que ocupam relativamente à respetiva cor focal ${ }^{15}$. Os adjetivos construídos com - ão (azulão, vermelhão) e com -inh- (vermelhinho), por seu turno, denotam não tons ou matizes, mas níveis saturados das cores referidas pelas respetivas bases.

A.2.2 Adjetivos denominais com os sufixos:

-áce- - azuláceo

-ad- - amarelado, azulado, rosado

\footnotetext{
${ }^{13}$ No âmbito do modelo SILEX, o símbolo " $\underline{\mathrm{o}}$ " antes de uma palavra indica que ela é possível mas não atestada nas fontes consultadas.

${ }^{14} \mathrm{Não}$ se encontra nenhum outro adjetivo denominal por sufixação que exiba esta terminação.

${ }^{15}$ Cor focal é o tom de uma categoria de cor que constitui o melhor exemplo dessa categoria - e.g. vermelho focal é o tom de vermelho que constitui o melhor exemplo de vermelho.
} 
-al - brancal, negral, verdeal

$-e-$ cínzeo

-ent- - amarelento, brancacento

-in- - azulino

-os- - negregoso, verdoso, vermelhoso

Os adjetivos denominais estabelecem um tipo de relação entre a sua base e a entidade que permitem modificar (o nome ao qual se associam). Em princípio, cada sufixo pertencente ao paradigma desta regra de construção de palavras permite que os respetivos adjetivos derivados exprimam um tipo particular de relação (posse, semelhança, proveniência, etc.), ainda que não se possa falar de uma estrita distribuição complementar entre eles. Estes princípios têm sido desenvolvidos em diferentes trabalhos enquadrados no modelo SILEX, tais como Corbin, D. \& P. 1991, Mélis-Puchulu 1991, Rio-Torto 1991, Correia 1999 (capítulo 3).

Os adjetivos apresentados neste item denotam tons das cores cujos nomes lhes servem de base, embora de forma imprecisa, tal como verificámos relativamente aos dados apresentados em A.2.1. O que se verifica nos dados de A.2.2. é que, se tomarmos em conta as definições lexicográficas propostas nos dicionários consultados, não é possível estabelecer uma regularidade que dê conta da especificidade semântica que o sufixo em princípio atribui ao derivado em que intervém, como é típico dos adjetivos denominais; por outro lado, não fica estabelecida uma relação clara entre o sufixo selecionado e o tipo de tom que é denominado pelo derivado, mais próximo ou mais distante da cor focal; por fim, destacam-se os casos de negregoso e de verdoso (aceção 2), que denotam um grau elevado de saturação da cor. Observem-se, a este propósito, os exemplos seguintes, retirados de GDLP:

- brancal: «esbranquiçado», negral: «de cor muito escura, quase negro; próximo do negro»; verdeal: «de cor esverdeada»;

- negregoso: «muito negro; muito escuro»; verdoso: «1 esverdeado; 2 verdejante», vermelhoso: «semelhante ao vermelho; avermelhado».

Esta ausência de regularidade pode, no entanto, ficar a dever-se apenas à qualidade dos dicionários. Trabalho baseado em corpora poderia trazer nova luz a estes dados.

A.2.3 Nomes deadjetivais com os sufixos:

-idão - amarelidão, branquidão, negridão, pretidão, roxidão, vermelhidão 
Para o estudo da denominação da cor em português...

-or - brancor, negror, verdor ${ }^{16}$

-ude - negritude

-ume - negrume, verdume

-ura - brancura, negrura, verdura, roxura

Os nomes construídos com estes sufixos são nomes de qualidade, isto é, nomes parafraseáveis por "qualidade de Adj" / "o facto de ser Adj" e, ao contrário dos nomes de cor não sufixados, dão a ver a qualidade apenas de forma intensiva e não de forma extensiva (cf. Correia 1999 e 2006), como pode verificar-se nas frases abaixo:

a) Este quadro tem muita vermelhidão (o vermelho do quadro é muito intenso, muito saturado).

vs.

b) Este quadro tem muito vermelho (o quadro tem uma parte significativa da sua superfície coberta de vermelho).

Note-se que é possível construir em português nomes deste tipo tomando por bases os restantes nomes de cor básicos, como pode verificar-se nos seguintes exemplos: ${ }^{o}$ azulidão, ${ }^{o}$ verdidão, ou ${ }^{o}$ vermelhura e ${ }^{o}$ cinzentura. Porém, é clara a resistência dos nomes de cor básicos diretamente provenientes de nomes de objetos (castanho, rosa, laranja) à adjunção de sufixos deste tipo - parecem muito menos naturais em português formas como ${ }^{o}$ castanhidão $/{ }^{o}$ castanhura; ${ }^{o}$ laranjidão / ${ }^{o}$ laranjura; ${ }^{\circ}$ rosidão / ${ }^{o}$ rosura .

A.2.4 Adjetivos e nomes deverbais

Tendo em conta os critérios seguidos na elaboração do nosso corpus de trabalho, não é de surpreender a presença de adjetivos deverbais em:

-nte - branquejante, negrejante, verdejante, reverdejante

-vel - branqueável

-dor - azulador, branqueador

Note-se que, enquanto os adjetivos em - dor denotam agentividade, sendo parafráseáveis por "que V", e o adjetivo em -vel é parafraseável por "que

\footnotetext{
${ }^{16}$ Em Correia 1999, -or foi excluído da lista dos sufixos atualmente disponíveis em português para a construção de nomes de qualidade, dado ter-se verificado que a maioria dos aparentes produtos deste processo não corresponde a construções realizadas nesta língua, mas sim a formas latinas que nela permaneceram. Admitese, porém, que esta opção possa ser revista à luz de uma análise com dados diferentes dos usados nesse trabalho, incluindo de forma sistemática dados do PB.
} 
pode ser V-ado", os adjetivos em - nte denotam graus de saturação elevados relativamente à cor cujo nome lhes serve de base.

Foram também detetados nomes deverbais em:

-(â)ncia - verdejância

-(d)ura - branqueadura

-mento - amarelecimento, azulamento, branqueamento, negrejamento, acinzamento, embranquecimento, enegrecimento, enverdecimento

Do mesmo modo, também os nomes deverbais em -(d)ura e -mento são nomes de ação, ao passo que o exemplo em -(ha)ncia é mais claramente um nome de qualidade denotando um elevado grau de saturação da cor.

Dado que estabelecemos como princípio não nos determos sobre verbos derivados de nomes de cor, não aprofundaremos a análise dos dados apresentados neste item, porque ela implicaria a análise dos verbos que lhes servem de base.

Importa, porém, salientar os seguintes casos pela produtividade e pela regularidade morfológica e semântica de que são prova:

- os adjetivos em -nte e o nome em - (̂a)ncia denotam graus saturados da cor cujo nome lhes serve de base, facto que resulta da semântica dos verbos que lhes estão na base - todos os verbos em - $e j$ - derivados sobre nomes de cor, atestados ou possíveis (e.g. ${ }^{o}$ vermelhejar, ${ }^{o}$ rosejar, ${ }^{o}$ cinzentejar $\left.{ }^{17}\right)$ são parafraseáveis por "exibir $\mathrm{X}$ de forma muito intensa, evidente", sendo X um nome de cor;

- os nomes deverbais cuja base é, por sua vez, um verbo derivado de um nome de cor são tipicamente construídos com recurso ao sufixo -mento, uma vez que este sufixo seleciona principalmente por base verbos incoativos.

\section{B. Composição}

O termo composição é tomado neste trabalho em sentido lato, incluindo estruturas relevantes de composição morfossintática $(\mathrm{N}+\mathrm{N})$ e de lexicalização seja de sintagmas, seja de unidades discursivas - cf. Correia \& Almeida 2012.

\footnotetext{
${ }^{17}$ É visível existirem restrições de ordem fonológica à construção de verbos por este processo - cf. a aparente agramaticalidade de formas como *laranjejar ou *roxejar.
} 
Os compostos apresentados neste item podem funcionar quer como nomes, quer como adjetivos, aspeto que não teremos, no entanto, em conta na descrição abaixo. Na descrição dos itens construídos por composição, deternos-emos apenas, portanto, nas categorias aparentes das unidades envolvidas na construção dos compostos, isto é, trataremos as unidades que denominam a cor genericamente como nomes.

B.1. $\mathrm{N}($ cor $)+\mathrm{N}$ (objeto)

- amarelo-canário, amarelo-topázio

- azul-cobalto, azul-ferrete, azul-pavão, azul-turquesa

- branco-marfim, branco-pérola

- verde-alface, verde-azeitona, verde-cré, verde-ervilha, verde-esmeralda, verde-gaio, verde-garrafa, verde-mar, verde-montanha, verde-salsa

- vermelho-púrpura

Todos os nomes desta categoria denominam tons ou graus de luminosidade da cor de base que se assemelham à cor apresentada prototipica ou estereotipicamente pelos objetos cujos nomes ocorrem na segunda posição dos compostos. O uso deste tipo de estruturas torna mais facilmente identificável a zona cromática visada, uma vez que o objeto selecionado faz em geral parte do universo de referência dos falantes. Destaque-se que, além de variação no tom, mais evidente, as cores denominadas por este processo denotam efetivamente também variação na luminosidade da cor - e.g. verde-gaio surge definido em GDLP como «verde-claro», verde-azeitona como «que apresenta o tom verde escuro, caraterístico da azeitona». Neste sentido, os nomes construídos por este processo constituem os termos de cor mais eficientes no que toca à precisão na denominação da cor, incluindo o tom e a luminosidade.

Será certamente essa eficácia denominativa aquilo que determina que, em determinados discursos especializados (moda, decoração, designação de coloração em geral - e.g. tintas, pigmentos, lápis de cor, aguarelas), sejam os termos com esta estrutura os mais frequentemente usados. Note-se que muitos outros nomes com esta estrutura existem e se encontram em uso na língua e que só não são aqui contemplados devido à limitação das fontes que selecionámos para a recolha dos dados. Carvalho 1994 havia já demonstrado a produtividade deste processo na formação de nomes de cor no âmbito da moda. Este facto pode ser explicado precisamente pela eficiência com que permitem delimitar o tom e a luminosidade em causa quando comparados, por exemplo, com as unidades construídas por sufixação - cf. A.2.2.

Note-se, ainda, que, também como Carvalho 1994 havia já verificado, os nomes de cor que dão origem a um maior número de compostos deste tipo são verde e $a z u l$, provavelmente pela dificuldade de distinção destas cores pelos 
falantes, ou, dito de outro modo, pela flexibilidade da fronteira entre ambas as cores no espetro cromático.

\section{B.2. $\mathrm{N}$ (cor) + Adjetivo}

Os nomes incluídos nesta categoria permitem, tal como os de B.1., denominar tonalidades das cores denominadas pelo nome núcleo do composto.

B.2.1. $\mathrm{N}+$ Adjetivo simples

- amarelo-claro, amarelo-escuro, amarelo-pálido

- azul-claro, azul-escuro

- verde-claro, verde-escuro, verde-velho, verde-rubro

- vermelho-escuro, vermelho-vivo

Os compostos deste grupo são aqueles que, na língua portuguesa, permitem com maior precisão dar conta da dimensão luminosidade da cor - cores mais luminosas aparecem qualificadas com claro, pálido, velho; cores menos luminosas, com escuro. Por seu turno, os adjetivos rubro e vivo quando apostos a nomes de cor permitem ao composto denotar graus elevados de saturação da cor visada.

B.2.2. $\mathrm{N}+$ Adjetivo denominal

- azul-celeste, azul-marinho

Os compostos incluídos neste grupo têm um funcionamento semântico semelhante ao dos compostos apresentados em B.1.: basicamente referem um tom da cor que é tida como semelhante à cor que estereotipicamente ostentam o céu (celeste) e o mar (marinho) - ${ }^{o} a z u l$-céu e ${ }^{o} a z u l-m a r$ seriam, do ponto de vista estritamente referencial, perfeitos equivalentes de, respetivamente, azul-celeste e azul-marinho.

B.2.3. $\mathrm{N}+$ Adjetivo deverbal

\section{- amarelo-torrado}

Este composto denomina um baixo grau de luminosidade («carregado») de amarelo, intervindo na sua construção uma metáfora.

B.2.4 N + Adjetivo de cor

verde-amarelado

vermelho-amarelado

Estes dois compostos denotam tons que não são prototípicos da cor denominada pelo núcleo do composto (não são tons focais), mas sim tons que se encontram na fronteira entre as duas cores neles integradas (verde e amarelo, por um lado; vermelho e amarelo, por outro, sendo que neste caso estaremos a falar de uma tonalidade (próxima) de laranja. Note-se que é difícil distinguir verde-amarelado de ${ }^{\circ}$ amarelo-esverdeado, por um lado, e vermelho-amarelado 
de ${ }^{\mathrm{O}}$ amarelo-avermelhado, por outro: provavelmente ambos os membros do par denotariam a mesma zona do espetro cromático, dado que, no entanto, é intuitivo e carece de verificação.

B.3. $\mathrm{N}($ cor $)+d e+\mathrm{N}$ (objeto)

- cor de laranja, cor de rosa

Estas duas formas coexistem na língua com os equivalentes morfologicamente simples rosa e laranja, o que pode ser um indicativo do facto de constituírem aquisições mais recentes da língua, confirmando aquilo que é postulado por Berlin \& Kay 1969/1999. No entanto, esta hipótese carece de estudo diacrónico que não foi possível levar a cabo no âmbito deste trabalho.

B.4. $\mathrm{N}($ cor $)+(e)+\mathrm{N}$ (cor)

- verde-branco, verdenegro, verde-negro

- preto-e-branco, verdinegro

Os compostos incluídos neste grupo permitem qualificar objetos que ostentam de modo relevante as duas cores envolvidas. Ainda que a regra envolvida na construção destes compostos permita qualquer combinação ( ${ }^{o}$ amarelo-azul, ${ }^{\circ}$ vermelho-roxo, etc.), a verdade é que se trata de uma estrutura muito pouco produtiva na língua, pelo menos a avaliar pelos dados contidos nos dicionários.

\section{Conclusão}

Ao longo deste trabalho, pudemos verificar que, além da conversão, que não foi alvo de estudo, vários são os processos disponíveis em português para a construção de nomes e adjetivos a partir dos nomes de cor básicos: derivação por sufixação, além de composição. A prefixação parece não constituir um processo disponível para a construção destes produtos. O processo mais produtivo em termos de número de unidades registadas é a derivação por sufixação, seguido da composição. Porém, dado que as fontes usadas no trabalho são basicamente lexicográficas, a conclusão esboçada relativamente à produtividade dos processos em análise não pode ser extrapolada para o léxico global do português:

- por um lado, os dicionários são pouco sistemáticos no registo dos termos relativos à cor, não apenas na seleção de entradas a incluir na nomenclatura (ou como subentradas de outros artigos), mas também na própria formulação da definição lexicográfica; 
- por outro lado, o menor número de nomes compostos pode ficar a deverse precisamente à forma menos sistemática como os dicionários registam entradas que constituem compostos, relativamente a entradas simples ou resultantes de derivação;

- por fim, note-se que um trabalho baseado em corpus como o de Carvalho 1994, em que a composição $\mathrm{N}$ (cor) + N (objeto) é o processo mais produtivo de construção de denominações da cor, vem contrariar as conclusões a que chegámos com base apenas nos dados contidos no VOP.

Em suma, não desdenhando dos dados contidos nos dicionários, que constituem a memória lexical da língua e que são relevantes instrumentos de trabalho para o lexicólogo e o morfólogo, entende-se que será necessário levar a cabo estudos mais extensos com dados recolhidos em corpora, de modo a obterse uma visão mais efetiva da produtividade dos processos disponíveis para a nomeação da cor. No entanto, a pesquisa em corpora extensos beneficiará certamente da existência de trabalhos do tipo do que aqui se apresenta e que pode ser entendido, neste sentido, como um estudo-piloto.

Num primeiro momento, podemos concluir que, enquanto os nomes de cor básicos denominam seja a cor de forma genérica, seja a cor focal, as palavras construídas a partir desses nomes permitem a nomeação de variantes da cor básica em função das suas três principais dimensões: o tom, a luminosidade e a saturação.

Verificámos, ainda, que, no âmbito dos produtos construídos, existem diferenças na forma de nomear entre os nomes e adjetivos derivados, por um lado, e os nomes e adjetivos compostos, por outro.

As palavras construídas por sufixação (A.2.1. e A.2.2.) permitem sobretudo nomear tons de cor, mas fazem-no de forma pouco precisa, ao passo que os compostos (B.1. e B.2.2.) são mais eficazes, mais precisos, na nomeação dos tons e da luminosidade, ao selecionarem para a sua construção o nome de um objeto que, prototipica ou estereotipicamente, apresenta o tom ou o grau de luminosidade em causa (amarelo-canário, azul-ferrete, verde-alface, azul-celeste). A produtividade de compostos do tipo apresentado em B.1. no discurso, que foi verificada por exemplo em Carvalho 1994, deve-se, então, à sua alta eficácia denominativa, dado que o recurso a entidades que em geral fazem parte do quotidiano dos falantes para identificar o tom ou a luminosidade a nomear permite uma delimitação mais clara, mais precisa da cor. De qualquer forma, serão necessários estudos mais sistemáticos, baseados em corpora, que complementem o trabalho de Carvalho 1994, pioneiro e importante, mas restrito ao domínio da moda em $\mathrm{PE}$. 
Ao nível da derivação afixal, verificou-se que existem processos disponíveis para a denominação de graus elevados de saturação da cor, nomeadamente a sufixação com recurso a - ão e a -inh- (azulão, vemelhão, vermelhinho) e, ainda, a construção de adjetivos em -nte e de nomes em -(h)ncia a partir de verbos em -ej- (verdejante, verdejância). Ao nível da composição, a denominação de graus elevados de saturação realiza-se apenas pelo recurso aos adjetivos rubro e vivo apostos ao nome da cor. Curiosamente, não se encontraram, pelo menos não nos dados usados, recursos morfológicos que explicitamente denotem graus baixos de saturação de cor; importará verificar em dados mais alargados, de corpora, se, por exemplo, alguns dos adjetivos derivados por sufixação permitem efetivamente a expressão desta categoria e não apenas denominação de tons ou matizes.

No que respeita à luminosidade, verificou-se que é sobretudo a composição (B.2.1.) o processo que permite denotar graus mais elevados ou mais baixos desta dimensão, pela aposição de adjetivos aos nomes de cor básicos - claro, pálido e velho para graus mais elevados de luminosidade e escuro para graus mais baixos.

Ficou patente, ainda, que a cor pode ser linguisticamente expressa em termos de intensidade com recurso a nomes de qualidade construídos com base nos adjetivos de cor (A.2.3.), por oposição à forma extensiva com que os demais nomes de cor o podem fazer - e.g. vermelhidão vs. vermelho.

Acreditamos ter evidenciado, com este trabalho, a pertinência do princípio, enunciado em 4., segundo o qual a estrutura morfológica escolhida para a denominação desempenha um papel importante na forma como a entidade nomeada é dada a ver.

Esta pesquisa poderá ser altamente enriquecida pelo desenvolvimento de estudos com base em corpora textuais alargados e, ainda, pelo estudo, constrastivo ou não, da denominação da cor nas demais variedades nacionais do português, nomeadamente em $\mathrm{PB}$, que, pela natureza do seu espaço-ambiente, poderão certamente trazer surpresas ao investigador.

Em suma, com este trabalho, acreditamos ter contribuído para o desenvolvimento de investigação no domínio da denominação da cor em português. 


\section{Bibliografia}

ANTUNES, Mafalda. 2012. Neologia de imprensa do português. Tese de doutoramento. Lisboa: Universidade de Lisboa.

BERLIN, Brent; KAY, Paul. 1969/1999. Basic Color Terms - Their Universality and Evolution. Stanford: CSLI Publications,

BIGGAM, Carole P.; KAY, Christian J. Eds. 2006. Progress in Colour Studies. Vol. I. Language and Culture. Amsterdam/Philadelphia: John Benjamins Publishing Company.

BIGGAM, Carole P.; HOUGH, Carole A.; KAY, Christian J.; e SIMMONS, David R.. Eds. 2011. New Directions in Colour Studies. Amsterdam/Philadelphia: John Benjamins Publishing Company.

CARVALHO, Anabela Morgado de. 1994. Nomes de cor num corpus especializado - moda e vestuário nos últimos trinta anos (contribuição para a descrição lexicográfica dos nomes de cor). Dissertação de Mestrado. Lisboa: Faculdade de Letras da Universidade de Lisboa.

CORBIN, Danielle. 1987. Morphologie dérivationnelle et structuration du lexique. 2 vols. Tubinga: Max Niemeyer Verlag.

CORBIN, Danielle. 1991. Introduction - La formation des mots: structures et interprétations. Lexique. 10: 7-30.

CORBIN, Danielle. 1997. La représentation d'une "famille" de mots dans le Dictionnaire dérivationnel du français et ses corrélats théoriques, méthodologiques et descriptifs. Recherches linguistiques de Vincennes, $\mathrm{n} .^{\mathrm{o}} 26$ : 5-37 + errata.

CORBIN, Danielle.; e CORBIN, Pierre. 1991. Un traitement unifié du suffixe-ier(e). Lexique. 10: 61-145.

CORREIA, Margarita. 1999. A denominação das qualidades - contributos para a compreensão da estrutura do léxico português. Tese de doutoramento. Lisboa: Universidade de Lisboa.

CORREIA, Margarita. 2002. A conversão em português, com principal incidência na construção de substantivos deadjectivais. In: Actas do Encontro Comemorativo dos 25 anos do Centro de Linguística da Universidade do Porto. vol. 2. Porto: Centro de Linguística da Universidade do Porto: 19-29.

CORREIA, Margarita. 2006. Towards a General Description of the Semantic Field of 'Colour' in European Portuguese. In: BIGGAM, Carole P.; KAY, Christian J. Eds.: 111-125.

CORREIA, Margarita.; e ALMEIDA, Gladis M. de Barcellos. 2012. Neologia do Português. São Paulo: Parábola Editorial. 
FERREIRA, J. P.; JANSSEN, M.; ALMEIDA, G. de B.; CORREIA, M.; e OLIVEIRA, G. M. de. 2012. The Common Orthographic Vocabulary of the Portuguese Language: a set of open lexical resources for a pluricentric language. In: CALZOLARI, N.; CHOUKRI, K.; DECLERCK, T.; DOĞGN, M. U.; MAEGAARD, B.; MARIANI, J.; ODIJK, J.; e PIPERIDIS, S. Eds. Proceedings of the Eight International Conference on Language Resources and Evaluation (LREC'12). [sl]: European Language Resources Association (ELRA): 1071-1075.

HARDIN, C. L.; e MAFFI, Luisa. Eds. 1997. Color Categories in Thought and Language. Cambridge: Cambridge University Press.

MacLAURY, Robert E.; PARAMEI, Galina V.; e DEDRICK, Don. Eds. 2007. Anthropology of Color. Amsterdam/Philadelphia: John Benjamins Publishing Company.

MELIS-PUCHULU, Agnès. 1991. Les adjectifs dénominaux: des adjectifs de "relation". Lexique. 10: 33-60.

PLÜMACHER, Martina; e HOLZ, Peter Eds. 2007. Speaking of Colors and Odors. Amsterdam/Philadelphia: John Benjamins Publishing Company.

REBELO GONÇALVES, Francisco. 1966. Vocabulário da Língua Portuguesa. Coimbra: Coimbra Editora.

RIO-TORTO, Graça Maria. 1991. Morphologie des adjectifs portugais en -ado. Lexique. 10: 241-267.

RIO-TORTO, Graça Maria. 1993. Formação de palavras em português: Aspectos da construção de avaliativos. Tese de doutoramento. Coimbra: Universidade de Coimbra.

RIO-TORTO, Graça Maria. 1998. Morfologia derivacional - teoria e aplicação ao português. Porto: Porto Editora.

SAID ALI, Manuel. 1931. Nomes de cores. Revista de Philologia e de Historia, I: 143-164.

SWEARINGEN, Andrew. 2002. Seeing Red in Roxo: the Evolution of a Portuguese Colour Term. Dissertação de Mestrado. Universidade de Copenhaga.

STEINVALL, Anders. 2002. English Colour Terms in Context. Umea University: Skrifter fran moderna sprak 3.

ZAVAGLIA, Cláudia. 1998. Aspectos semânticos dos cromônimos entre as línguas italiana e portuguesa do Brasil. Estudos Lingüisticos, v. 27: 912-917.

ZAVAGLIA, Cláudia. 2006. Dicionário e Cores. Alfa, v. 50: 25-41.

ZAVAGLIA, Cláudia. 2008. Quem tem boca vai a Roma: as cores dos provérbios. In: Isquerdo, A. N. \& M. J. B. Finatto. Orgs. As ciências do 
léxico. Lexicologia, Lexicografia e Terminologia. Vol. IV. Campo Grande: Editora da UFMS: 113-131.

ZAVAGLIA, Cláudia.; e ZAVAGLIA, Adriana. 2000. A elaboração de um dicionário trilíngüe temático de cromônimos italiano-português-francês/francêsportuguês-italiano: reflexões e considerações. Cadernos do Cnlf, v. 1, n. 10: 19-29.

ZAVAGLIA, Cláudia.; e ZAVAGLIA, Adriana. 2007. A prática lexicográfica multilíngüe: questões concernentes ao campo das cores. In: Isquerdo, A. N. \& I. M. Alves Orgs. As Ciências do Léxico: Lexicologia, Lexicografia, Terminologia. v. III. Campo Grande; São Paulo: Ed. UFMS; Humanitas: 209-222.

\section{Outros recursos}

\section{Dicionários gerais de língua}

CASTELEIRO, João Malaca. Coord. 2001. Dicionário da Língua Portuguesa Contemporânea. 2 vols. Lisboa: Academia das Ciências de Lisboa / Editorial Verbo - referido no texto como DLPC.

COSTA, Margarida; SILVA, Sofia. Coords. 2010. Grande Dicionário Lingua Portuguesa. 2. ${ }^{\mathrm{a}}$ ed. Porto: Porto Editora - referido no texto como GDLP.

\section{Corpora online}

ROCHA, Paulo; SANTOS, Diana. 2000. CETEMPúblico. Disponível em http://www.linguateca.pt/cetempublico/

DAVIES, Mark; e FERREIRA, Michael. 2006- . Corpus do Português (45 milhões de palavras, sécs. XIV-XX). Disponível em www.corpusdoportugues.org.

\section{Bases de dados morfológicos}

CORREIA, Margarita. Coord. 2010. Vocabulário Ortográfico do Português. Disponível em www.portaldalinguaportuguesa.org.

Recebido em: $30 / 11 / 2012$

Aceito em: 16/01/2013 